\title{
Analysis of Inflammatory Mediators in Type 2 Diabetes Patients
}

\author{
Ahmed Al-Shukaili, ${ }^{1}$ Saif AL-Ghafri, ${ }^{2}$ Safia Al-Marhoobi, ${ }^{3}$ Said Al-Abri, ${ }^{4}$ \\ Jawad Al-Lawati, ${ }^{5}$ and Masoud Al-Maskari ${ }^{2}$ \\ ${ }^{1}$ Health \& Social Development Sector, The Research Council of Oman, P.O. Box 1422, 130 Muscat, Oman \\ ${ }^{2}$ Emergency Departments, Sultan Qaboos University Hospital (SQUH), P.O. Box 35, 123 Muscat, Oman \\ ${ }^{3}$ Studies \& Planning, Statistics Section, The Research Council, P.O. Box 1422, 130 Muscat, Oman \\ ${ }^{4}$ Public Health, Armed Forces Medical Services Headquarters, Ministry of Defense, P.O. Box 928, 13 Muscat, Oman \\ ${ }^{5}$ Department of Non-Communicable Diseases Surveillance and Control, Ministry of Health, P.O. Box 393, 100 Muscat, Oman
}

Correspondence should be addressed to Ahmed Al-Shukaili; ashukaily@hotmail.com

Received 5 March 2013; Accepted 10 April 2013

Academic Editor: Ilias Migdalis

Copyright ( 2013 Ahmed Al-Shukaili et al. This is an open access article distributed under the Creative Commons Attribution License, which permits unrestricted use, distribution, and reproduction in any medium, provided the original work is properly cited.

\begin{abstract}
The main aim of this study is to assess the inflammatory markers in type 2 diabetes mellitus (T2DM) by measuring some cytokines concentrations and lymphocytes subset and correlate them with other laboratory investigations. Fifty-seven patients with type2 diabetes and 30 healthy volunteers were enrolled in this study. Data for the C-reactive protein (CRP), haemoglobin, HbAlc, and autoantibody levels were obtained from the patients files. The cytokine concentrations were measured in patient's serum using commercially available ELISA assays. Lymphocytes subsets were measured by flow cytometric methods. The levels of IL$1 \beta$, IL-6, IL-15, and TNF- $\alpha$ were found to be decreased in T2DM patients, whereas the levels of IL-10, IFN- $\gamma$, and caspase- 1 were increased, compared to normal controls. T2DM patients with hypertension show significantly decreased levels of IL-1 $\beta$ and caspase1 compared to patients without hypertension. No significant differences in lymphocytes subset between cases and normal control were observed. Significant correlations were found between HbAlc and IL-6; body mass index (BMI) was significantly correlated with CRP, TNF- $\alpha$, and phosphate; the weight (Wt) was associated with CRP and IFN- $\gamma$. In conclusion, an alteration in the function of the immune system was observed in T2DM patient.
\end{abstract}

\section{Introduction}

Type 2 diabetes mellitus (T2DM) represents a significant global health problem. The burden of diabetes has increased sharply in Oman over the last decade, rising from 8.3\% in 1991 to $11.6 \%$ in 2000 , and $12.3 \%$ in 2008 among adults aged 20 years and older $[1,2]$.

Inflammation is considered to be a key regulator of the pathogenesis of T2DM, but what triggers this inflammation still unknown [3]. However, it may be related to obesity. Obesity is associated with enlargement of adipose tissue and consequently increases the number of adipose tissue macrophages $[4,5]$. These macrophages are responsible for almost all adipose tissue tumor necrosis factor- $\alpha$ (TNF$\alpha$ ) expression, significant amounts of interleukin-6 (IL-6), and other acute-phase response markers and mediators of inflammation [5-7].
Many proinflammatory cytokines play a central role in inflammatory reaction and were shown to increase the risk of T2DM $[8,9]$. These pro-Inflammatory cytokines can enhance insulin resistance directly in adipocytes, muscle and hepatic cells, leading to systemic disruption of insulin sensitivity and impaired glucose homeostasis. Increased levels of these pro-inflammatory cytokines lead to hepatic production and secretion of acute-phase proteins such as $\mathrm{C}$-reactive protein (CRP), plasminogen activator inhibitor-1 (PAI-1), amyloidA, $\alpha 1$-acid glycoprotein, and haptoglobin. These proteins appear in the early stages of T2DM, and their circulating concentrations increase as the disease progresses $[3,8-10]$.

It has been reported that normal individuals with detectable levels of IL-1 $\beta$ and elevated levels of IL- 6 had an independently increased risk to develop T2DM, whereas those with increased concentrations of IL- 6 but undetectable levels of IL-1 $\beta$ had no significantly increased risk $[11,12]$. 
Another study showed that levels of IL-6, TNF- $\alpha$, and TNF-receptor were elevated in insulin-treated, but not in sulfonylurea-treated patients [13]. Moreover, levels of serum glucose, pro-inflammatory cytokines (IL-6, IL-12, and TNF$\alpha$ ), endothelial dysfunction markers (vascular cell adhesion molecule-1 (VCAM-1), intercellular adhesion molecule1 (ICAM-1), and nitric oxide), and lipid abnormality were highest in T2DM with cardiovascular complications [14]. Recently, it has been shown that T2DM patients had a significantly higher CD14 (+) CD16 (+) fluorescence intensity, TLR4 expression, and serum IL-6 and C-reactive protein (CRP) levels, compared to normal controls [15].

Here in this study, we extend the analysis of the role of inflammation in T2DM by measuring the levels of several cytokines, including IL-1, IL-6, IL-10, IL-15, IFN- $\gamma$, TNF$\alpha$, and caspase- 1 in T2DM and correlate them with other laboratory investigations. We will also examine whether there is an alteration in lymphocytes subsets in T2DM compared to the normal controls.

\section{Patients and Methods}

Fifty-seven patients (28 male, and 29 females, mean age $52 \pm 11.5)$ with type 2 diabetes and 30 healthy volunteers (20 male, and 10 females, mean age $35 \pm 7$ ) were enrolled in this study (Table 1). Patients attended the outpatients clinic at Sultan Qaboos University Hospital (SQUH), Muscat, Oman. Confirmed T2DM patients were selected randomly; however, cases associated with other inflammatory diseases such as cancer or autoimmunity were excluded from this study. Informed consent was obtained from each subject. The Medical Research and Ethics Committee (MREC) at the College of Medicine, Sultan Qaboos University (SQU), approved this study.

Data for the C-reactive protein (CRP), hemoglobin, HbAlc and autoantibody levels were obtained from the patients files. The cytokine concentrations were measured in patients sera using commercially available ELISA assays (R\&D Systems), performed according to the manufacturer's instructions. The lymphocytes subset was measured using monoclonal antibodies available as a Multiset panel (BD, USA, and analyzed using FACSCalibur flow cytometry (BD, USA), equipped with automated program.

2.1. Statistical Analysis. Statistical analyses were performed using SPSS software (20.0 version). Data normality was tested using KS test. Quantitative data were presented as mean \pm SD. The statistical significance between means was estimated by Student's $t$-test (independent samples) when appropriate. Pearson's correlation coefficient $(r)$ was used to measure the strength of the association between the two variables. Differences were considered statistically significant at $P<$ 0.05 .

\section{The Results}

3.1. Cytokines Levels. The levels of IL-1 $\beta$, IL-6, and IL-15 TNF- $\alpha$ were decreased in T2DM patients compared to
TABLE 1: Demographic information and laboratory investigations of the T2DM patients.

\begin{tabular}{lcc}
\hline \multirow{2}{*}{ Characteristics } & \multicolumn{2}{c}{ Mean \pm SD/n $(\%)$} \\
& T2DM patients & Healthy controls \\
\hline Age & $52.3 \pm 11.5$ & $35 \pm 7$ \\
Sex & & \\
$\quad$ Male & $28(49)$ & $20(67 \%)$ \\
$\quad$ Female & $29(51)$ & $10(33 \%)$ \\
Disease duration & & \\
$\quad \geq 5$ years & $51(89.4)$ & NA \\
$\quad<5$ years & $6(10.6)$ & \\
Height & $158.8 \pm 7.8$ & $165 \pm 10$ \\
Weight & $76.8 \pm 13.8$ & $73 \pm 10.2$ \\
BMI & $30.4 \pm 5.2$ & NA \\
HbAlc & $8.2 \pm 1.4$ & NA \\
CRP & $11.1 \pm 24.6$ & NA \\
Vitamin D & $44.2 \pm 20.2$ & NA \\
Hypertension & $38(67)$ & 0 \\
TC & $5.1 \pm 1.1$ & NA \\
LDL & $3.1 \pm 1.0$ & NA \\
HDL & $1.2 \pm 0.4$ & NA \\
TG & $1.6 \pm 1.1$ & NA \\
Current smokers & $2(3.5)$ & 0 \\
Treatment (\%) & & \\
Insulin & $12(21)$ & \\
Oral $\quad$ NA & \\
$\quad$ Oral + insulin & $5(16)$ & \\
Diet + exercise & $5(9)$ & \\
\hline
\end{tabular}

T2DM: type 2 diabetes mellitus; BMI: body mass index; HbAlc: glycated haemoglobin; CRP: C-reactive protein; TC: total cholesterol; LDL: lowdensity lipoprotein; HDL: high-density lipoprotein; TG: triglycerides. NA: not available.

normal controls (Figure 1). Mean baseline level of IL-1 (211 \pm $132 \mathrm{pg} / \mathrm{mL}$ ) was lower among T2DM compared with control subjects $(672 \pm 385 \mathrm{pg} / \mathrm{mL})$ but statistically insignificant $(P$ value $=0.157)$.

However, the mean value of IL-6 was significantly ( $P$ value of 0.0001$)$ lower in T2DM cases $(1.76 \pm 2.5 \mathrm{pg} / \mathrm{mL})$, compared to control subjects $(43 \pm 20 \mathrm{pg} / \mathrm{mL})$. The mean value of IL-15 was $4 \pm 2.9 \mathrm{pg} / \mathrm{mL}$, which is also significantly lower $(P$ value $=0.004)$ than the mean value for the controls $(10.2 \pm 10.3 \mathrm{pg} / \mathrm{mL})$. Similar significant difference $(P$ value $=$ $0.00002)$ was observed for TNF- $\alpha$; the mean baseline levels were $13 \pm 11 \mathrm{pg} / \mathrm{mL}$ for T2DM patients and $147 \pm 160 \mathrm{pg} / \mathrm{mL}$ for the control subjects.

When the patients' data was sorted according the treatment (insulin or sulfonylurea), no significant difference was observed between those patients treated with insulin only or those patients treated with sulfonylurea (data not shown).

The levels of IL-10, IFN- $\gamma$, and caspase-1 were increased in T2DM patients compared to normal controls (Figure 2). 


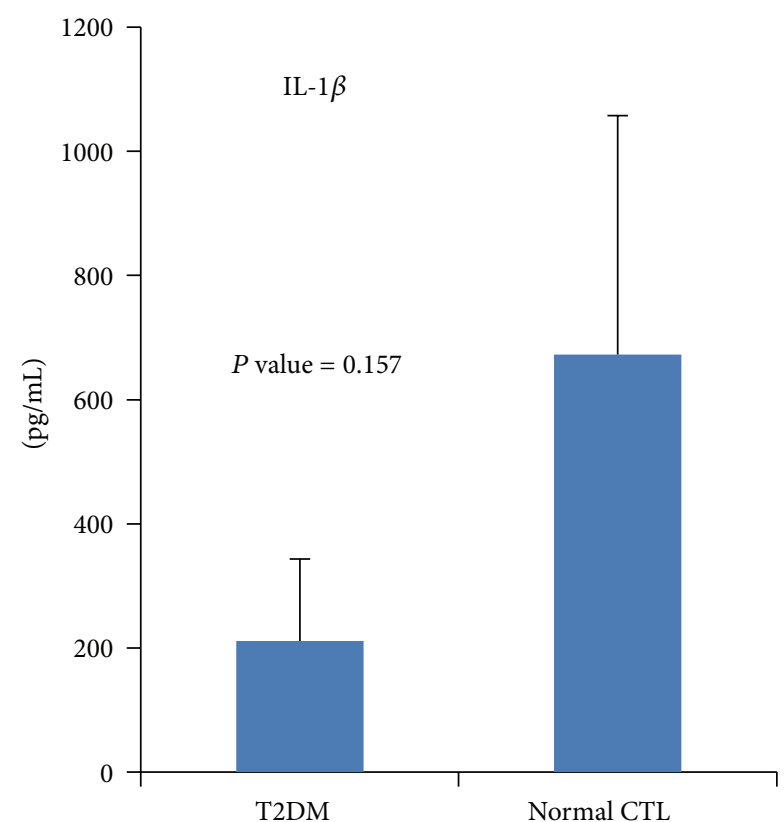

(a)

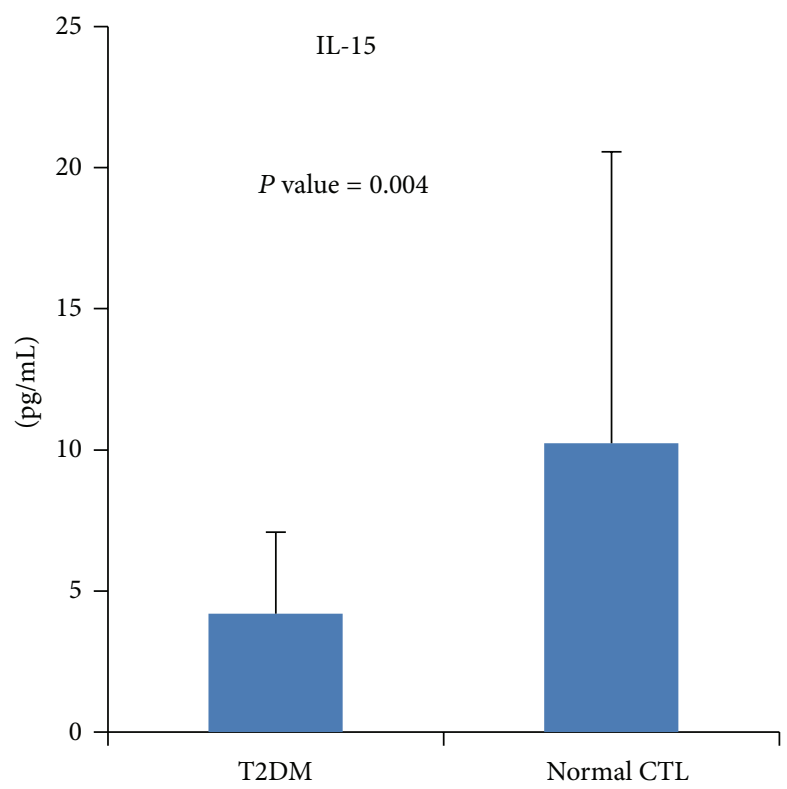

(c)

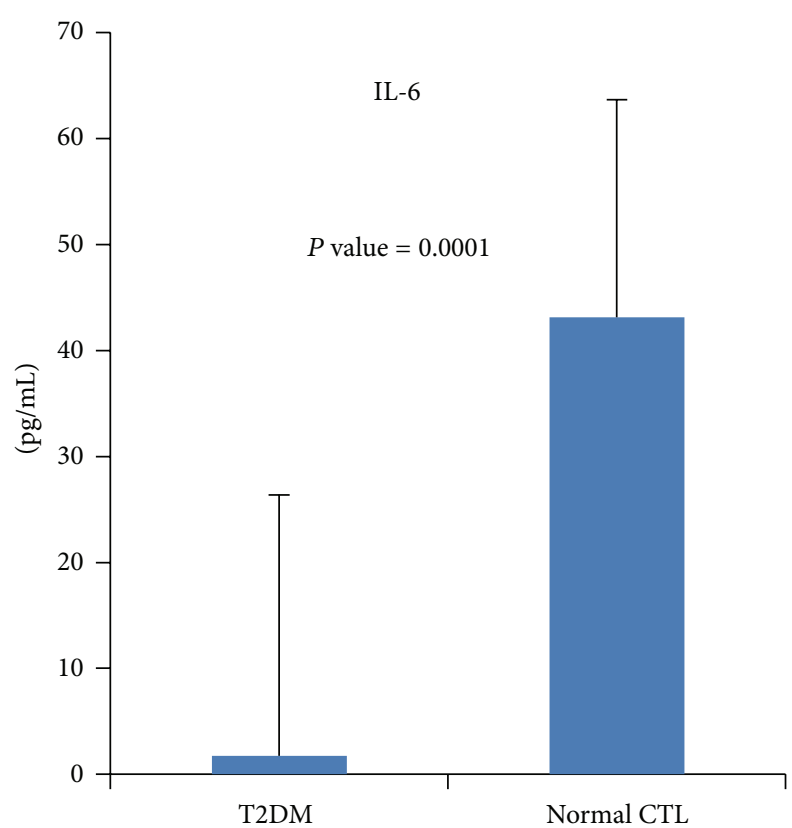

(b)

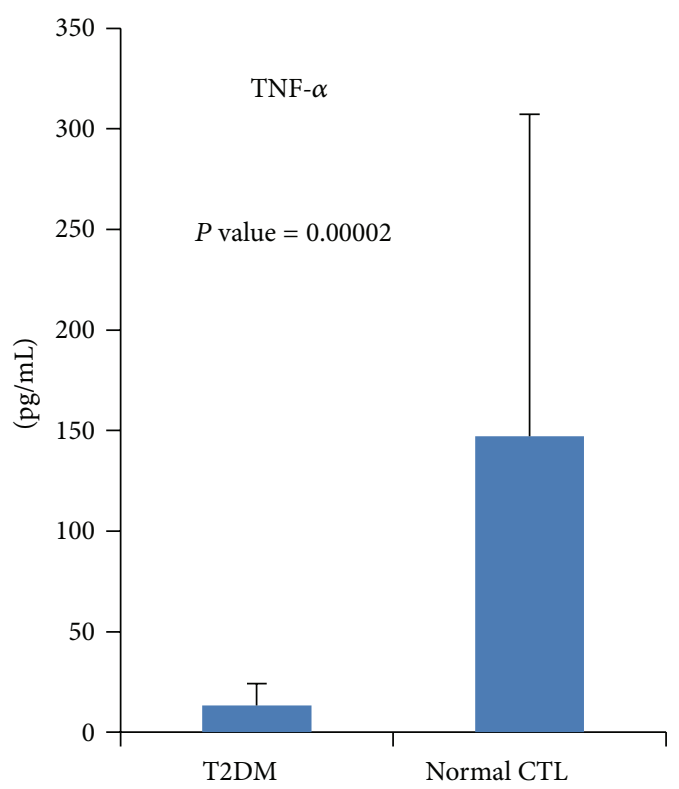

(d)

Figure 1: Decreased cytokine profile in T2DM.

Mean baseline levels of IL-10 $(6.95 \pm 6 \mathrm{pg} / \mathrm{mL})$ were significantly higher $(P$ value $=0.012)$ among T2DM patients compared to control subjects $(2.9 \pm 5.15 \mathrm{pg} / \mathrm{mL})$. Likewise, the mean value of caspase- 1 was $95.9 \pm 116 \mathrm{pg} / \mathrm{mL}$, which is significantly higher $(P$ value $=0.0005)$ than the mean value for the control $(20.2 \pm 15 \mathrm{pg} / \mathrm{mL})$. However, no significant differences were observed in the levels of IFN- $\gamma$ between patients $(2.97 \pm 4 \mathrm{pg} / \mathrm{mL})$ and controls $(1.8 \pm 4.1 \mathrm{pg} / \mathrm{mL})$.

When the patient's data was distributed according to the treatment, no significant difference was observed between patients in insulin only or patients treated with sulfonylurea; this is obviously because of the very small number in both groups; a large cohort should be used in the future.

3.2. Effect of Hypertension on Cytokine Production. T2DM Patients with hypertension show decreased levels of proinflammatory cytokines (Figure 3). Interestingly; T2DM patients with hypertension shows significantly decreased levels of IL- $1 \beta$ and caspase-1 ( $P$ value $=0.024,0.028$, resp.). TNF- $\alpha$ and IL-15 levels were also decreased but statistically insignificant. IL-6 and IL-10 levels were slightly increased in T2DM patients with hypertension. 


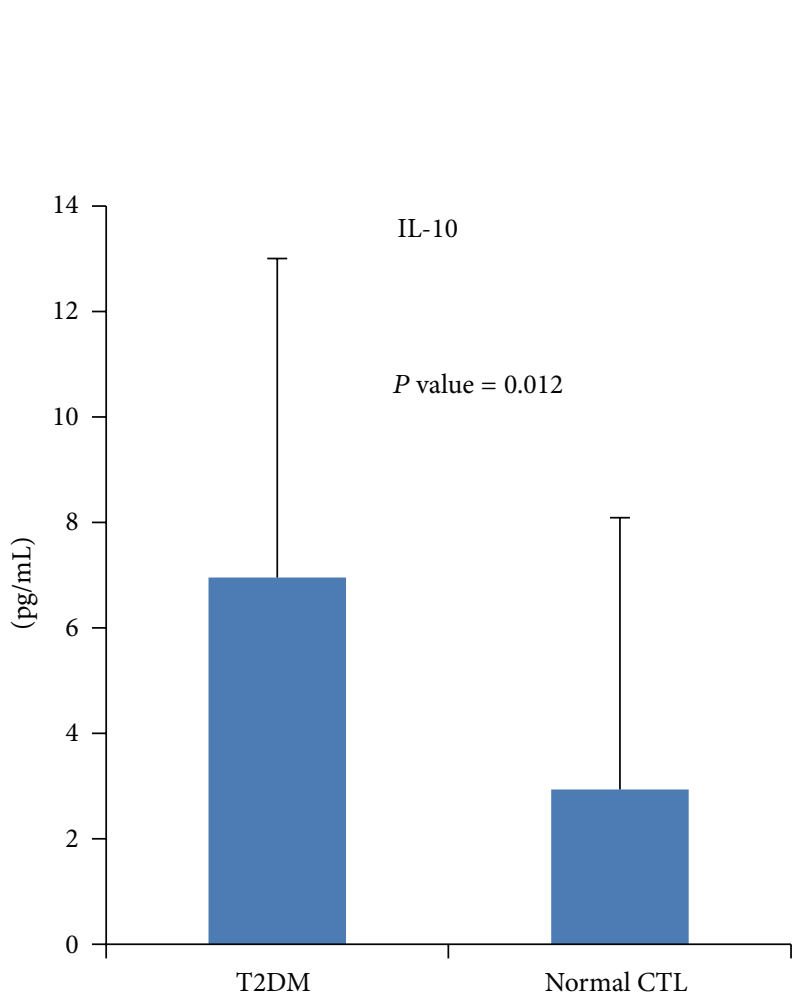

(a)

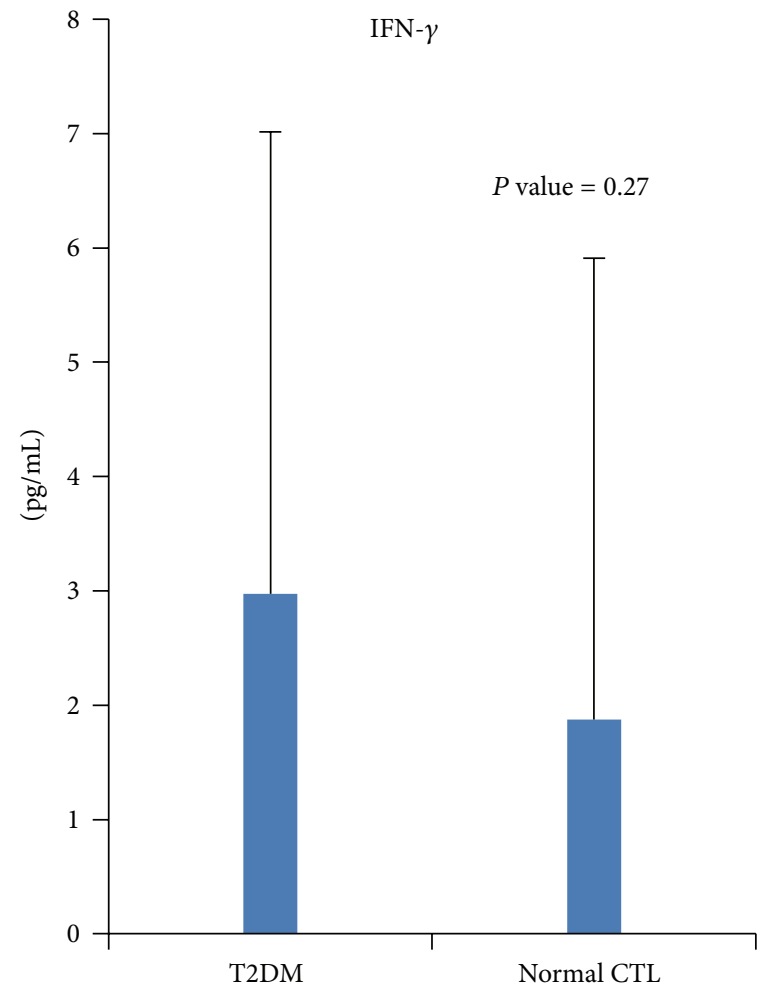

(b)

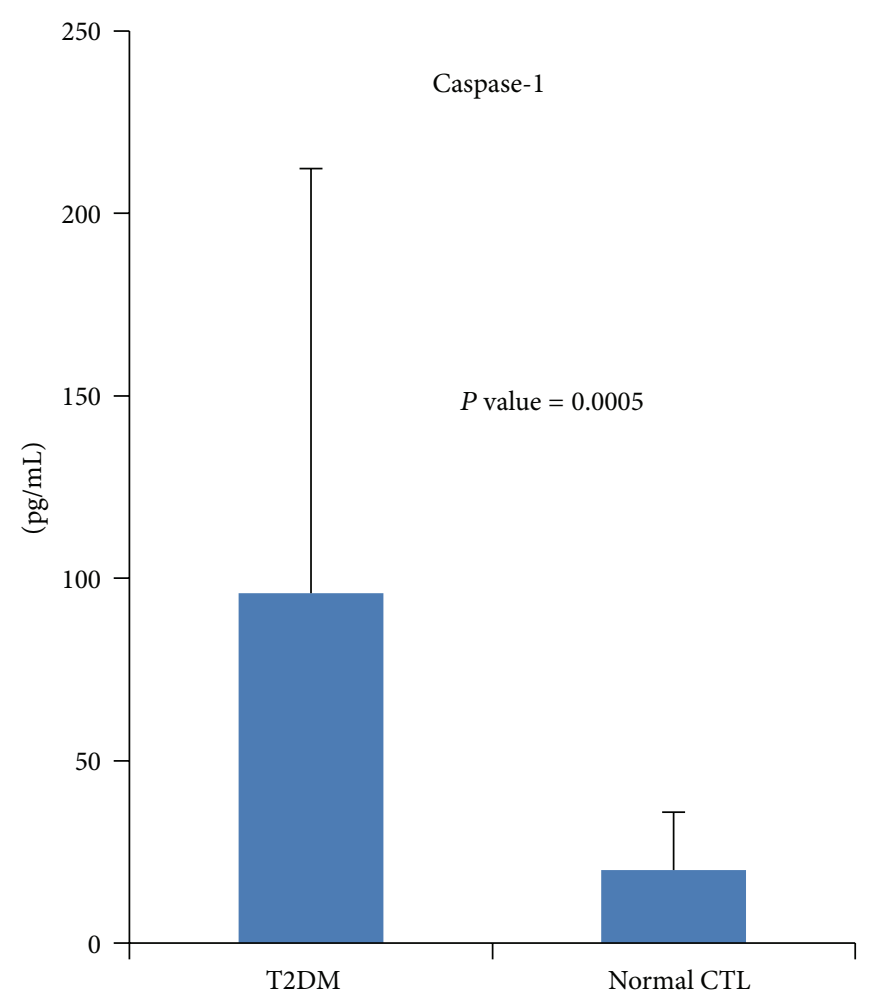

(c)

FIGURE 2: Increased cytokine profile in T2DM. 


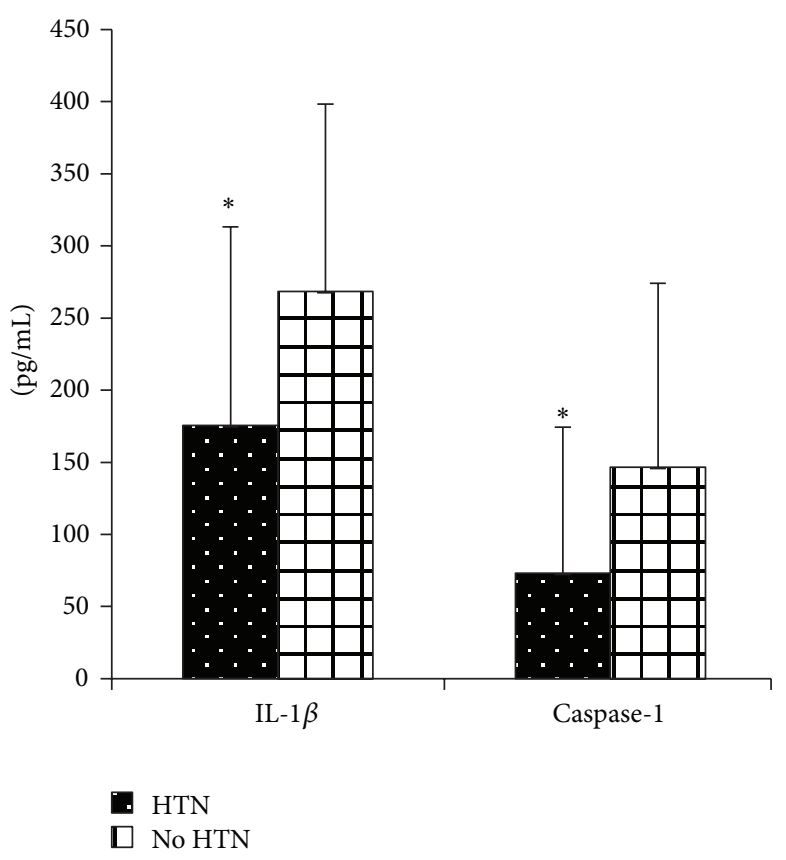

(a)

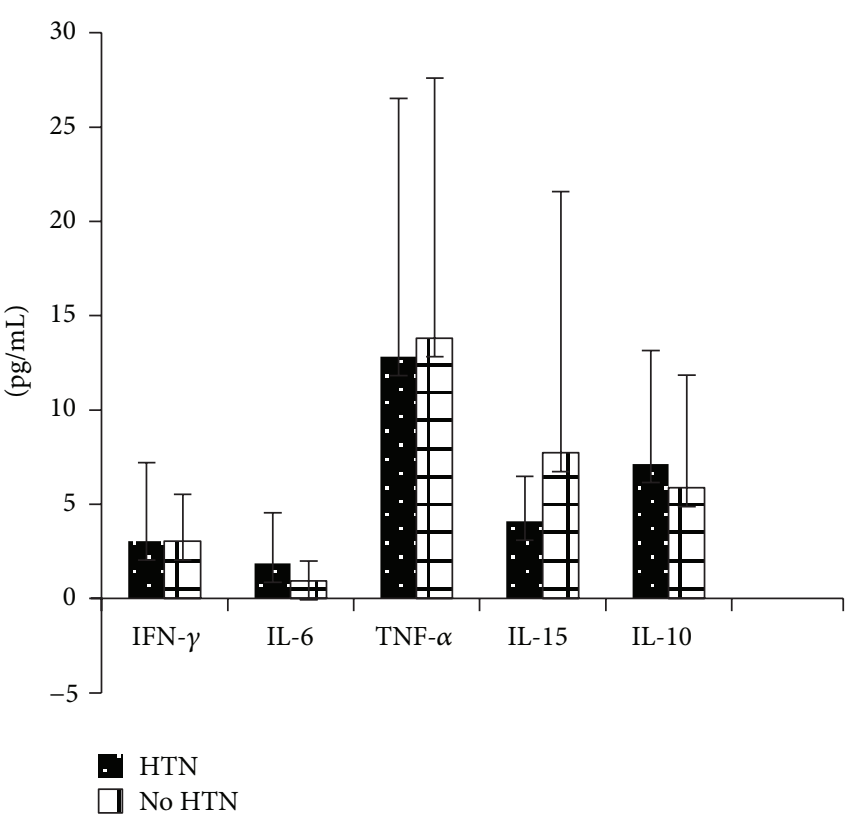

(b)

Figure 3: Cytokine profile in T2DM with or without hypertension. ${ }^{*}$ Significant difference $(P$ value $<0.05)$.

TABLE 2: Lymphocytes subset in T2DM and normal controls.

\begin{tabular}{|c|c|c|c|c|c|c|}
\hline & CD3+ & CD8+ & CD4+ & $\mathrm{CD} 4+/ \mathrm{CD} 8+$ & CD56+ & CD19+ \\
\hline Normal control, $n=30$ & $69 \pm 8.14$ & $25 \pm 5$ & $38 \pm 8$ & $0.7 \pm 1$ & $12 \pm 5$ & $14 \pm 4.7$ \\
\hline $\mathrm{T} 2 \mathrm{DM}, n=59$ & $71 \pm 8.9$ & $27 \pm 8.2$ & $43 \pm 7.5$ & $0.75 \pm 1$ & $14 \pm 7.5$ & $13 \pm 4.7$ \\
\hline$P$ value & NS & NS & NS & NS & NS & NS \\
\hline
\end{tabular}

NS: not significant.

3.3. Lymphocyte Subsets. Lymphocytes subsets in T2DM and normal controls are shown in Table 2; several immune cells were measured, including lymphocytes (CD3+), $\mathrm{T}$ helper cells $(\mathrm{CD} 4+)$, T-cytotoxic cells $(\mathrm{CD} 8+)$, double positive CD4/CD8, natural killer cells (CD56+), and B cells (CD19+), and no significant differences between T2DM patients and normal controls were observed, Table 2 .

3.4. Correlation Analysis. HbAlc was positively correlated with IL-6 with a significant $P$-value of 0.005 , and BMI was positively and significantly correlated with CRP $(P$ value $=$ $0.001)$, TNF- $\alpha(P$ value $=0.013)$ and phosphate $(P$ value $=$ $0.008)$. The weight (Wt.) of the patients was significantly correlated with CRP and IFN- $\gamma, P$ values of 0.11 and 0.044 , respectively. In addition, calcium level was correlated with phosphate $(P$ value $=0.004)$, hypertension $(P$ value $=0.032)$, LDL $(P$ value $=0.03)$ and dyslipidemia $(P$ value $=0.011)$, Table 3.

\section{Discussion}

Our data showed decreased levels of IL- $1 \beta$, IL-6, IL-15, and TNF- $\alpha$ and increased levels of IL-10, IFN- $\gamma$, and caspase- 1 in T2DM compared to healthy controls. Decreased levels of inflammatory cytokines in our study were in disagreement with previous findings. A recent study by Marques-Vidal et al. (2013) found that subjects with T2DM had increased levels of IL-6, TNF- $\alpha$, and hs-CRP, while no association was found with IL-1 $\beta$ [16]. Moreover, it was reported that, high levels of inflammatory cytokines appear in early stage of T2DM and capable of predicting the development of type 2 diabetes through diminishing insulin sensitivity $[9,10]$. This discrepancy can be attributed to the (I) duration of the diseases; the majority of patients included in our study have a long disease duration (greater than 5 years), (II) small sample size, and (III) the differences in age and sex of the studied groups; the age of the normal controls was lower than that of T2DM patients. Moreover, there were only 10 females on controls versus 29 females on T2DM group. These factors may have played essential roles in the cytokine production among these two study groups.

Mavridis et al. investigated inflammatory cytokines in insulin-treated T2DM patients and showed increased levels of IL-6, TNF- $\alpha$ in insulin-treated T2DM patients compared to sulfonylurea-treated patients. Also, they found a positive association between waist circumference and IL- 6 and a significant correlation between HbAlc and IL-6 [13]. When 
TABLE 3: Correlation analysis; data shows significant $P$ value.

\begin{tabular}{lcccccccc}
\hline & IL-6 & CRP & IFN- $\gamma$ & TNF- $\alpha$ & Phosphate & HTN & LDL & Dyslipidemia \\
\hline HbAlc & 0.005 & - & - & - & - & 0.008 & - & - \\
BMI & - & 0.001 & - & 0.013 & - & - & - \\
Wt. & - & 0.011 & 0.044 & - & - & - & - \\
Calcium & - & - & - & - & 0.004 & 0.032 & 0.030 & 0.011 \\
\hline
\end{tabular}

HbAlc: glycated haemoglobin; BMI: body mass index, Wt.: weight; CRP: C-reactive protein, HbAlc: glycated haemoglobin; TG: triglycerides; LDL: low-density lipoprotein; HTN: hypertension; TNF- $\alpha$ : tumor necrosis factor; IL-6: interleukin-6; IFN- $\gamma$ : interferon.

we sorted our data of cytokines levels, according to the treatment (insulin or sulfonylurea) of the patients, we did not find any significant differences; this may be due to a small sample size in our study. However, our results showed that HbAlc levels were correlated with IL-6 levels, which is in accordance with previous findings [11, 12]. Nevertheless, from all these data, we cannot conclude whether poor glycaemic control leads to inflammation or whether inflammation leads to higher glucose levels; further studies are needed to assess such questions.

Moreover, our study showed that BMI was positively correlated with CRP, TNF- $\alpha$, and phosphate levels; and the weight was positively correlated with CRP and IFN- $\gamma$, which is in accordance with previous findings [16-18]. This correlation can be explained as follows: obesity is associated with enlargement of adipose tissue and consequently increases the number of adipose tissues macrophages [4-6]. These macrophages are responsible for almost all adipose tissue TNF- $\alpha$ expressions and other acute-phase response markers and mediators of inflammation [5-7]. TNF- $\alpha$, secreted by adipose tissue, may play a critical role in insulin resistance and the pathogenesis of type 2 diabetes. Several studies indicated that increased levels of cytokines and acute-phase proteins can participate in maintaining the insulin-resistant state $[16,19]$.

In T2DM patients with hypertension, the pathophysiology of cardiovascular disease is multifactorial; for example angiotensin II may be to a large degree responsible for triggering vascular inflammation by inducing oxidative stress [20]. However, our data shows that T2DM patients with hypertension had significantly lower levels of IL- $\beta$ and Caspase- 1 and slightly higher levels of IL- 6 and IL10 , compared to patients with no hypertension. This can be attributed to the treatment of hypertension, such that drugs that target the renin-angiotensin system may reduce blood pressure and inflammation in T2DM patients with hypertension [20].

In conclusion, we found that, patients with established T2DM, had different cytokine profile than healthy controls, without a significant change in lymphocyte subsets; this indicates that, there is an alteration in the function of the immune system in T2DM patient.

\section{References}

[1] A. Al-Shookri, G. L. Khor, Y. M. Chan, S. C. Loke, and M. AlMaskari, "Type 2 diabetes in the Sultanate of Oman," Malaysian Journal of Nutrition, vol. 17, no. 1, pp. 129-141, 2011.
[2] J. A. Al-Lawati, M. N. Barakat, M. Al-Maskari, M. K. Elsayed, A. M. Al-Lawati, and A. J. Mohammed, "HbAlc levels among primary healthcare patients with type 2 diabetes mellitus in Oman,” Oman Medical Journal, vol. 27, no. 6, pp. 465-470, 2012.

[3] J. C. Pickup and M. A. Crook, "Is type II diabetes mellitus a disease of the innate immune system?" Diabetologia, vol. 41, no. 10, pp. 1241-1248, 1998.

[4] R. Goyal, A. F. Faizy, S. S. Siddiqui, and M. Singhai, "Evaluation of TNF- $\alpha$ and IL- 6 levels in obese and non-obese diabetics: preand post-insulin effects," North American Journal of Medical Sciences, vol. 4, no. 4, pp. 180-184, 2012.

[5] S. Cinti, G. Mitchell, G. Barbatelli et al., "Adipocyte death defines macrophage localization and function in adipose tissue of obese mice and humans," Journal of Lipid Research, vol. 46, no. 11, pp. 2347-2355, 2005.

[6] S. P. Weisberg, D. McCann, M. Desai, M. Rosenbaum, R. L. Leibel, and A. W. Ferrante, "Obesity is associated with macrophage accumulation in adipose tissue," Journal of Clinical Investigation, vol. 112, no. 12, pp. 1796-1808, 2003.

[7] K. Popko, E. Gorska, A. Stelmaszczyk-Emmel et al., "Proinflammatory cytokines Il- 6 and TNF- $\alpha$ and the development of inflammation in obese subjects," European Journal of Medical Research, vol. 15, pp. 120-122, 2010.

[8] F. B. Hu, J. B. Meigs, T. Y. Li, N. Rifai, and J. E. Manson, "Inflammatory markers and risk of developing type 2 diabetes in women," Diabetes, vol. 53, no. 3, pp. 693-700, 2004.

[9] M. I. Schmidt, B. B. Duncan, A. R. Sharrett et al., "Markers of inflammation and prediction of diabetes mellitus in adults (atherosclerosis risk in communities study): a cohort study," The Lancet, vol. 353, no. 9165, pp. 1649-1652, 1999.

[10] A. Festa, R. D’Agostino Jr., R. P. Tracy, and S. M. Haffner, "Elevated levels of acute-phase proteins and plasminogen activator inhibitor-1 predict the development of type 2 diabetes: the insulin resistance atherosclerosis study," Diabetes, vol. 51, no. 4, pp. 1131-1137, 2002.

[11] A. D. Pradhan, J. E. Manson, N. Rifai, J. E. Buring, and P. M. Ridker, "C-reactive protein, interleukin 6, and risk of developing type 2 diabetes mellitus," The Journal of the American Medical Association, vol. 286, no. 3, pp. 327-334, 2001.

[12] J. Spranger, A. Kroke, M. Möhlig et al., "Inflammatory cytokines and the risk to develop type 2 diabetes: results of the prospective population-based european prospective investigation into cancer and nutrition (EPIC)-potsdam study," Diabetes, vol. 52, no. 3, pp. 812-817, 2003.

[13] G. Mavridis, E. Souliou, E. Diza et al., "Inflammatory cytokines in insulin-treated patients with type 2 diabetes," Nutrition, Metabolism and Cardiovascular Diseases, vol. 18, no. 7, pp. 471476, 2008.

[14] M. Mishra, H. Kumar, S. Bajpai, R. K. Singh, and K. Tripathi, "Level of serum IL-12 and its correlation with endothelial 
dysfunction, insulin resistance, proinflammatory cytokines and lipid profile in newly diagnosed type 2 diabetes," Diabetes Research and Clinical Practice, vol. 94, no. 2, pp. 255-261, 2011.

[15] M. Yang, H. Gan, Q. Shen, W. Tang, X. Du, and D. Chen, "Proinflammatory $\mathrm{CD} 14^{+} \mathrm{CD} 16^{+}$monocytes are associated with microinflammation in patients with type 2 diabetes mellitus and diabetic nephropathy uremia," Inflammation, vol. 35, no. 1, pp. 388-396, 2012.

[16] P. Marques-Vidal, F. Bastardot, R. von Känel et al., "Association between circulating cytokine levels, diabetes and insulin resistance in a population-based sample," Clinical Endocrinology, vol. 78, no. 2, pp. 232-241, 2013.

[17] L. Utsal, V. Tillmann, M. Zilmer et al., "Elevated serum IL-6, IL8, MCP-1, CRP, and IFN- $\gamma$ levels in 10- to 11-year-old boys with increased BMI," Hormones Research and Pediatric, vol. 78, no. 1, pp. 31-39, 2012.

[18] L. Khaodhiar, P. R. Ling, G. L. Blackburn, and B. R. Bistrian, "Serum levels of interleukin-6 and C-reactive protein correlate with body mass index across the broad range of obesity," Journal of Parenteral and Enteral Nutrition, vol. 28, no. 6, pp. 410-415, 2004.

[19] J. J. Senn, P. J. Klover, I. A. Nowak, and R. A. Mooney, "Interleukin-6 induces cellular insulin resistance in hepatocytes," Diabetes, vol. 51, no. 12, pp. 3391-3399, 2002.

[20] C. Savoia and E. L. Schiffrin, "Reduction of C-reactive protein and the use of anti-hypertensives," Vascular Health and Risk Management, vol. 3, no. 6, pp. 975-983, 2007. 


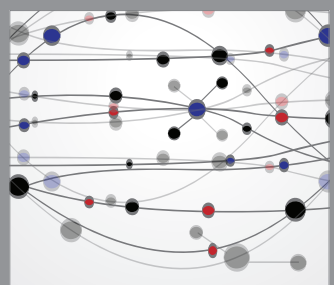

The Scientific World Journal
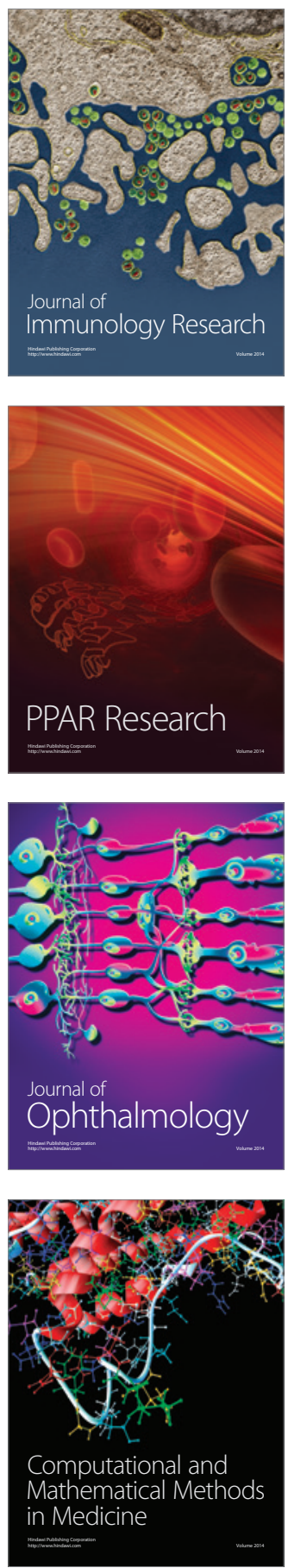

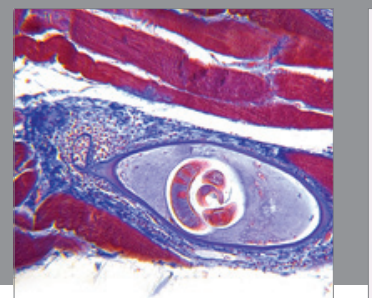

Gastroenterology

Research and Practice
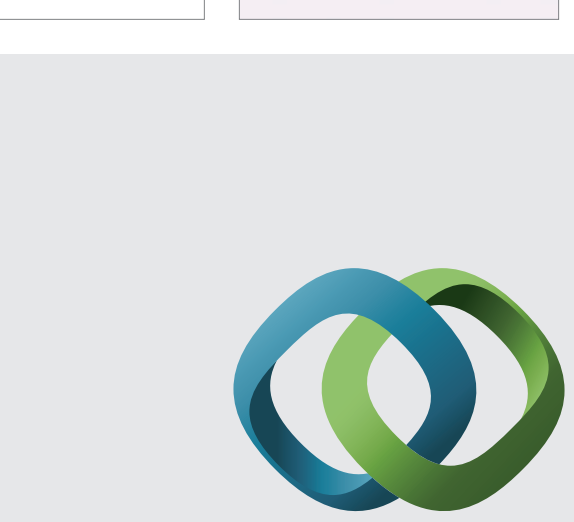

\section{Hindawi}

Submit your manuscripts at

http://www.hindawi.com
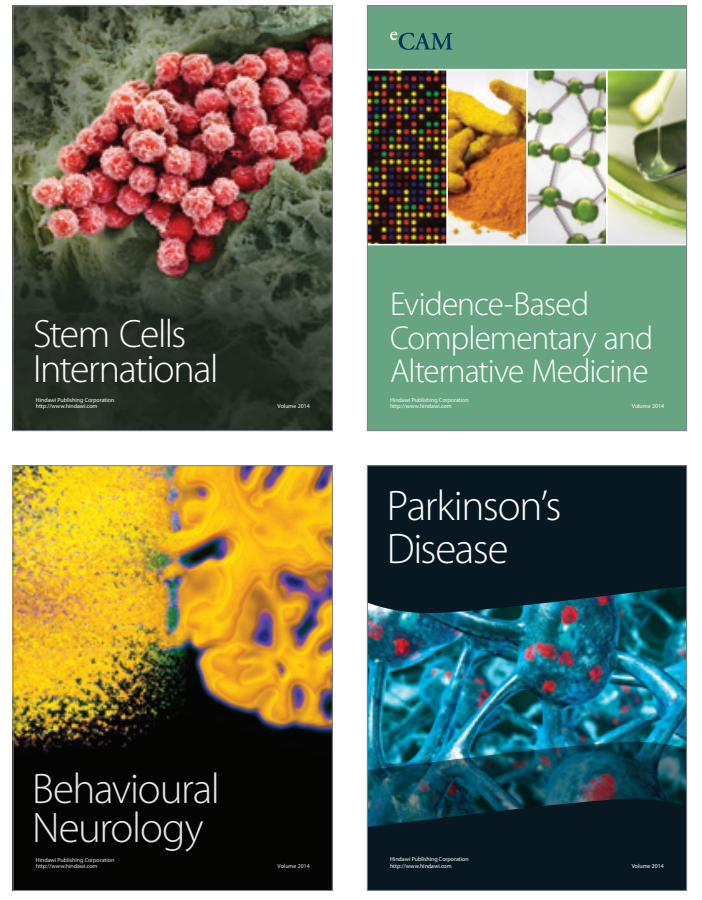
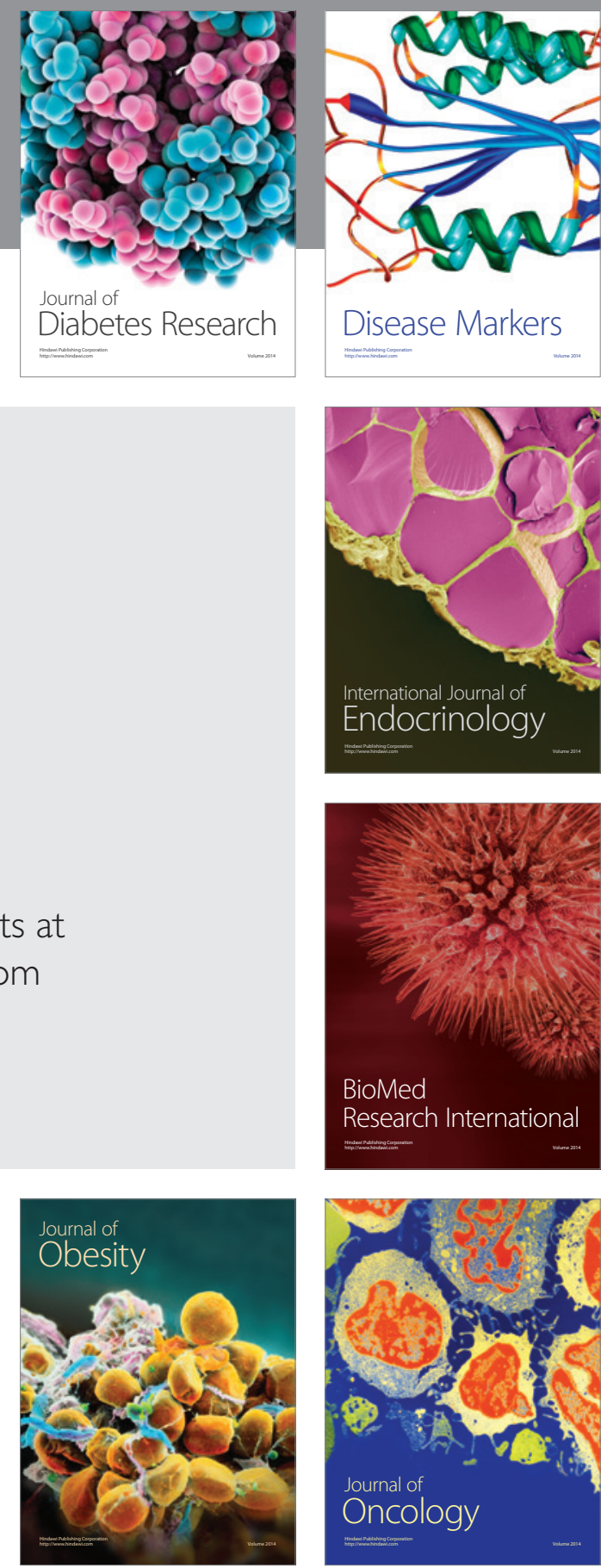

Disease Markers
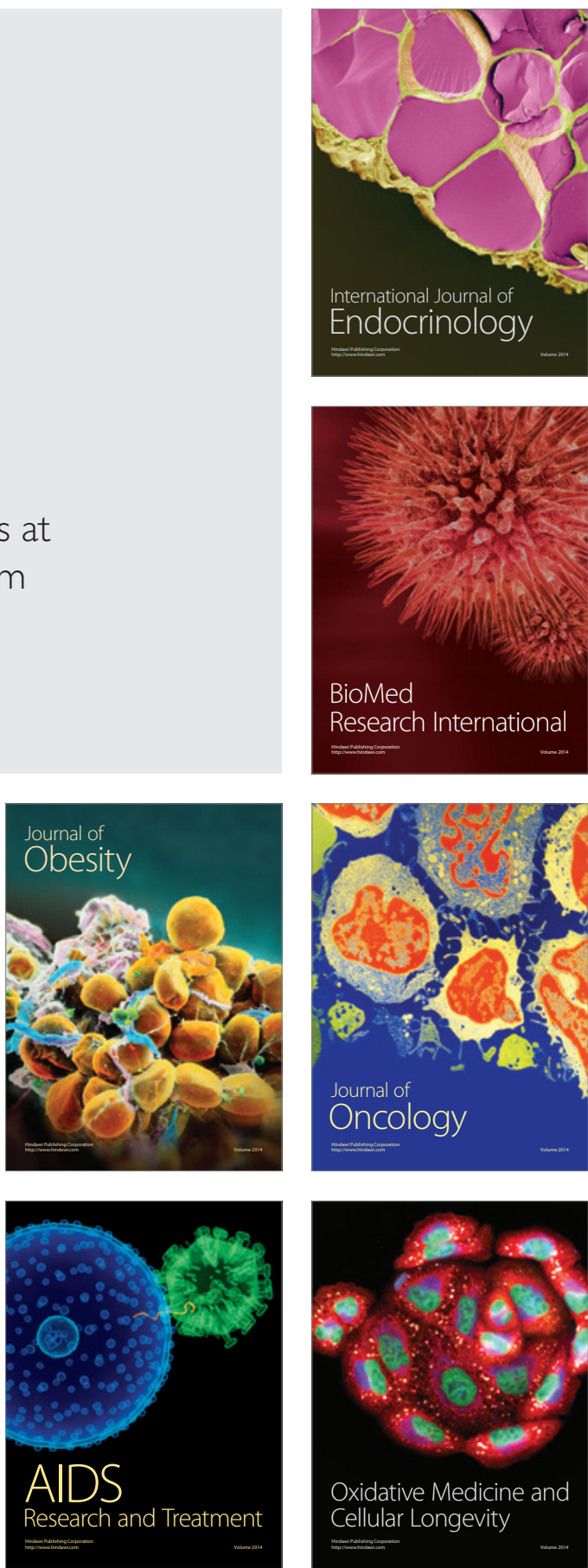